\title{
Numerical study of cavitating flow inside a flush valve
}

\author{
Annie-Claude Bayeul-Lainé ${ }^{1, a}$, Sophie Simonet ${ }^{1}$, Daniel Dutheil ${ }^{2}$ \\ AND GuY CAIGNAERT ${ }^{1}$ \\ 1 Arts et Métiers Paristech, LML, UMR CNRS 8107, 8 boulevard Louis XIV, 59046 Lille Cedex, France \\ 2 PRESTO, 4 rue Lavoisier, 17110 Saint Georges de Didonne, France
}

Received 15 February 2011, Accepted 27 September 2011

\begin{abstract}
In water supply installations, noise pollution often occurs. As a basic component of a system, a flush valve may frequently be a source of noise and vibration generated by cavitation or high turbulence levels. During valve closing or valve opening, cavitation can be a problem. In order to decrease the noise and to improve the design inside a flush valve, some experimental and numerical analyses were carried out in our laboratories. These analyses led to some improvements in the design of the valves. Cavitation occurrence was more specifically addressed, using numerical simulation, and this is the main aim of the present paper. Particularly, the use of a simplified numerical test without cavitation model is compared with one using a cavitation model. In order to define potential cavitation risks in some parts of the valve, it has been found that a simplified approach provides an accurate overview. Computational Fluid Dynamics (CFD) simulations of cavitating flow of water through an industrial flush valve were performed using the Reynolds averaged Navier-Stokes (RANS) equations with a near-wall turbulence model. The flow was assumed turbulent, incompressible and steady. Two commercial CFD codes (Fluent 6.3 and Star CCM+ 3.04.009) were used to analyse the effects of inlet pressure as well as mesh size and mesh type on cavitation intensity in the flush valve.
\end{abstract}

Key words: Cavitation / noise / numerical simulation / water supply systems

Résumé - Étude numérique d'un écoulement cavitant dans un robinet de chasse d'eau. Il arrive souvent que des problèmes de pollution sonore se produisent dans les conduites d'installation sanitaire. Un robinet de chasse d'eau peut être à l'origine de bruit et de vibrations liés à un phénomène de cavitation, ou d'écoulement tourbillonnaire néfaste, particulièrement lors de l'ouverture ou de la fermeture de ce robinet. Afin de diminuer le bruit tout en améliorant l'écoulement dans un robinet de chasse d'eau, des études numériques et expérimentales ont été menées au sein de nos laboratoires. Ces études ont permis de proposer des améliorations de forme du robinet et de mettre en évidence des problèmes de cavitation potentiels dans certaines conditions de fonctionnement. Le but du présent article est de proposer un outil numérique pragmatique et rapide de détection de la cavitation sans utiliser un code spécifique avec un modèle de cavitation. Cette approche montre une bonne cohérence avec les résultats obtenus en utilisant un modèle de cavitation. Les simulations numériques de l'écoulement cavitant dans le robinet de chasse d'eau ont été réalisées en utilisant les équations de Navier Stokes moyennées (RANS) avec un modèle de turbulence près des parois. L'écoulement est supposé turbulent, incompressible et stationnaire. Le robinet de chasse d'eau modélisé est un robinet industriel. Du fait de la symétrie du robinet, seule la moitié du robinet a été modélisée. Les effets de la pression d'entrée, du type de maillage, de la taille des mailles sur l'intensité de la cavitation (évaluée par l'intensité de la pression) dans le robinet de chasse d'eau ont été étudiés en utilisant deux codes de calcul commerciaux : Fluent 6.3 and Star CCM+ 3.04.009.

Mots clés : Cavitation / bruit / simulation numérique / installations sanitaires

\footnotetext{
${ }^{a}$ Corresponding author: annie-claude.bayeul@ensam.eu
} 


\section{Nomenclature}

\begin{tabular}{|lll|}
\hline$N_{\text {bub }}$ & {$[-]$} & number of vapour bubbles in a control volume \\
$N_{\text {cells }}$ & {$[-]$} & number of cells \\
$N_{\mathrm{it}}$ & {$[-]$} & number of iterations \\
$N_{\mathrm{pl}}$ & {$[-]$} & number of prism layers \\
$Q$ & {$\left[\mathrm{~kg} \cdot \mathrm{s}^{-1}\right]$} & mass flow rate \\
$Q_{\text {ref }}$ & {$\left[\mathrm{kg} \cdot \mathrm{s}^{-1}\right]$} & reference mass flow rate \\
$R$ & {$[\mathrm{~m}]$} & micro bubble radius \\
$U$ & {$\left[\mathrm{~m} \cdot \mathrm{s}^{-1}\right]$} & velocity \\
$V_{\mathrm{l}}$ & {$\left[\mathrm{m}^{3}\right]$} & volume of liquid in a control volume \\
$V_{\mathrm{v}}$ & {$\left[\mathrm{m}^{3}\right]$} & volume of vapour in a control volume \\
$e_{1}$ & {$[\mu \mathrm{m}]$} & first prism layer thickness \\
$e_{\mathrm{t}}$ & {$[\mu \mathrm{m}]$} & total prism layer thickness \\
$p_{\mathrm{min}}$ & {$[\mathrm{MPa}]$} & minimum absolute static pressure \\
$p$ & {$[\mathrm{MPa}]$} & static pressure \\
$p_{\mathrm{i}}$ & {$[\mathrm{MPa}]$} & static pressure at valve inlet \\
$p_{\text {iref }}$ & {$[\mathrm{MPa}]$} & static reference pressure at valve inlet \\
$t_{\mathrm{ref}}$ & {$[\mathrm{s}]$} & reference time \\
$t$ & {$[\mathrm{~s}]$} & time \\
$u^{+}$ & {$[-]$} & dimensionless velocity \\
$u_{\tau}$ & {$\left[\mathrm{m} \cdot \mathrm{s}^{-1}\right]$} & friction velocity \\
$v_{\mathrm{max}}$ & {$\left[\mathrm{m} \cdot \mathrm{s}^{-1}\right]$} & maximum velocity in narrow flow passage \\
$w a l l ~ y$ & {$[-]$} & dimensionless distance \\
$x, y, z$ & {$[\mathrm{~m}]$} & cartesian coordinates \\
$y^{+}$ & {$[-]$} & dimensionless distance \\
$\alpha_{\mathrm{l}}$ & {$[-]$} & liquid volume fraction \\
$\alpha_{\mathrm{v}}$ & {$[-]$} & vapour volume fraction \\
$\nu$ & {$\left[\mathrm{m}{ }^{2} \cdot \mathrm{s}^{-1}\right]$} & kinematic viscosity \\
$\rho$ & {$\left[\mathrm{kg} \cdot \mathrm{s}^{-1}\right]$} & mass density \\
$\tau_{\mathrm{w}}$ & {$[\mathrm{Pa}]$} & surface shear stress \\
\hline & &
\end{tabular}

\section{Introduction}

One of the most important parameters in building construction is noise control. Cavitation noise generated by components such as valves in water supply systems has frequently raised serious problems. In each country, there are legal codes of practice, and today new building sites and major construction projects are well controlled. Taps and valves can, therefore, be classified on the basis of their acoustic behaviour, in accordance with the ISO 3822 or NF EN 12541 standards [1,2].

In order to determine the sources of noise and the best design methods to minimize noise generation, experimental and numerical analyses were carried out in our laboratories.

The present paper shows the results of numerical investigations regarding the prediction of cavitation in such devices. The main objective was to propose an efficient enough methodology in order to help the manufacturer during the design phase for the development of new products.

Figures 1 and 2 describe flow rate and upstream static pressure evolutions during one operating cycle, from opening to closure, in a non-dimensional form. Such tests results are obtained in an open test rig composed of: (i) a vessel with a control of pressure, (ii) a steel pipe with a laminar flow element flow meter, (iii) a deformable pipe in order to limit pressure surges during the valve closure, (iv) a pipe with various pressure transducers upstream of the tested valve.

The main aim of such a valve is to deliver a fixed volume of liquid (6 or $9 \mathrm{l}$ ) with a high enough momentum. It is clear, from these two figures, that the operation of such a valve is unsteady and transitory. Nevertheless, the cycle duration (about $10 \mathrm{~s}$ ) allows to consider the flow inside the valve as a succession of quasi-steady operating conditions. This is the main assumption that has been made in the present study, because, up to now, CFD codes are not really able to describe accurately such a transitional behaviour with a control of the opening and closure of the valve by the flow itself.

Various noise sources have been identified in flush valves [3]. Cavitation occurrence when the flow goes through the valve is recognized as an important noise source and thus has to be controlled during the design phase of a new product. The present paper deals with this problem. Cavitation occurs when pressure in the liquid drops below the vapour pressure. Vapour bubbles are formed, and rapidly collapse when pressure increases. That collapse of bubbles is associated with noise generation $[4,5]$.

Gao et al. [6] showed the importance of predicting cavitation in water hydraulic valve and the necessity of investigation.

During closing or opening of this type of valve, static pressure remains relatively constant before and behind 


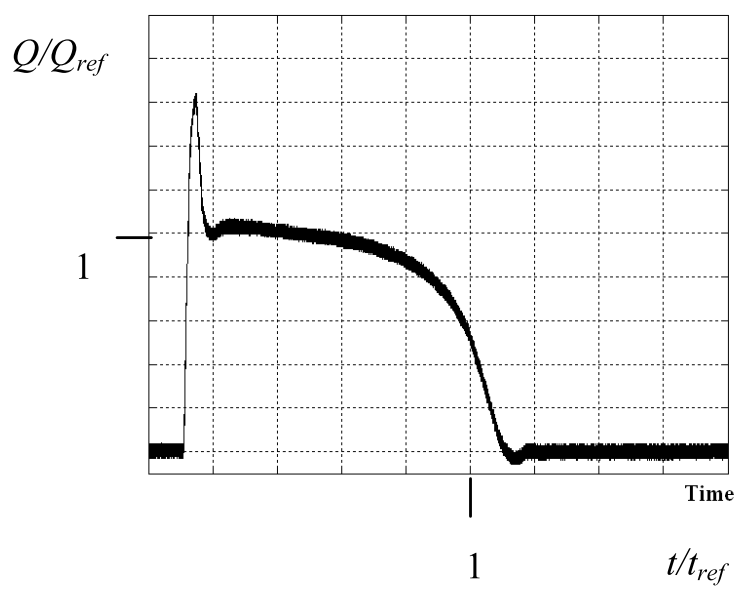

Fig. 1. Flow rate in a flush valve during a cycle (nondimensional presentation).

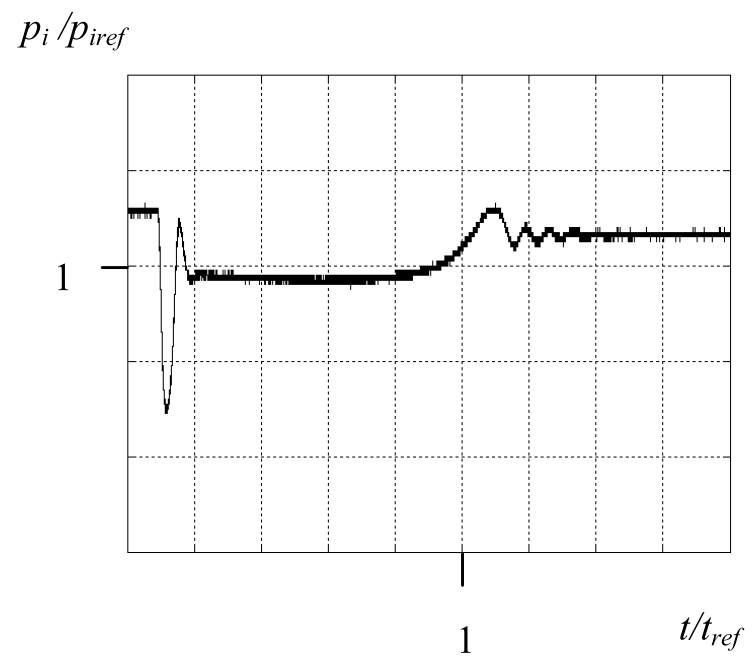

Fig. 2. Upstream static pressure in a flush valve during a cycle (non-dimensional presentation).

the gap formed by piston and seat. Most of the head drop occurs in that gap [detail (a) in Fig. 4] that is called "narrow flow passage" in the text hereafter.

The cavitation model in commercial CFD codes, designed for two interpenetrating fluids (generally liquid and vapour phases of the same fluid), describes the formation of bubbles when the local pressure becomes lower than the vapour pressure. The cavitation model solves a single set of momentum equations shared by the two fluids, a continuity equation for the liquid (primary phase) and a volume fraction equation for the secondary phase. It is assumed that all vapour bubbles in a control volume have the same radius $R$ and a homogenous distribution. This assumption leads to using a single scalar field, the vapour volume fraction $\alpha_{\mathrm{v}}$.

$$
\alpha_{\mathrm{v}}=\frac{V_{\mathrm{v}}}{V}=\frac{N_{\mathrm{bub}} \frac{4}{3} \pi R^{3}}{V_{\mathrm{l}}+V_{\mathrm{v}}}
$$

Assuming that only one liquid phase (volume $V_{1}$ ) and the corresponding liquid-vapour phase (volume $V_{\mathrm{v}}$ ) can occupy a control volume $V$ where cavitation takes place. The mass of produced vapour depends on the vapour density, on the anticipated average size (radius $R$ ) and on the vapour bubbles density. Cavitation model also accounts for mass transfer between the fluids. Models in commercial codes can predict the inception of cavitation but few can predict the collapse of the bubbles.

Cavitation is a complex process influenced by a lot of factors. The formation of bubbles followed by their collapse makes the flow highly unsteady. Consequently we have to choose between steady or unsteady approaches for cavitation. In both cases, simulation takes a lot of time. The occurrence of cavitation is confirmed with that steady approach.

This paper shows how a commercial CFD code can point out a cavitation problem without the straightforward usage of a cavitation model.

Two commercial codes were used: Fluent 6.3 and Star CCM+ 3.04.009 [7,8].

Both codes are applying finite volume methods [7-12]. Conservation equations of mass, momentum, mixture fraction and additional turbulence models equations are solved. In each code, the fluid is supposed to be incompressible.

In Fluent, the pressure-based solver is used. In the pressure-based approach, the pressure field is extracted by solving a pressure correction equation which is obtained by manipulating continuity and momentum equations. The pressure-based solver uses an algorithm in which the constraint of mass conservation (continuity) of the velocity field is achieved by solving a pressure correction equation. The pressure field is derived from the continuity and the momentum equations in such a way that the velocity field, corrected by the pressure, satisfies the continuity [9]. Since the governing equations are nonlinear and coupled, the solution process involves iterations so the entire set of governing equations is solved repeatedly until the solution converges. In Fluent two pressure-based solver algorithms are available: segregated (for incompressible fluid) and coupled algorithm (often used for compressible fluid). Segregated algorithm has been used in this paper due to hypothesis of incompressibility.

In Star CCM+, discrete versions of the integral forms of the continuum transport equations are applied to each control volume. The objective is to obtain a set of linear algebraic equations, with the total number of unknowns in each equation system corresponding to the number of cells in the grid. As the equations are non-linear, iterative techniques that rely on suitable linearization strategies must be employed. The resulting linear equations are then solved with an algebraic multigrid solver [10-15]: some of the work could be done on a coarse grid, since computations on coarse grids are much less costly. Multigrid algorithms use three stages:

1. Agglomerate cells to form coarse grid levels

2. Transfer residuals from a fine level to a coarser level 


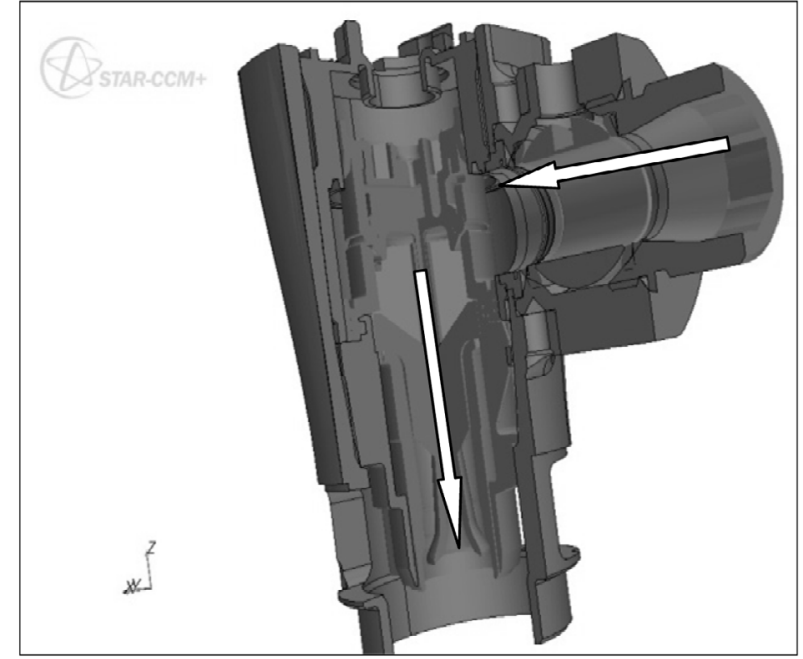

Fig. 3. Flush valve geometry (cut $3 / 4$ view).

- Transfer the correction from a coarse level back to a finer level.

Fluent CFD code is used first with a steady flow hypothesis, for a comparison between two models: with no cavitation model and with cavitation model. A comparison between the two CFD codes is then made. Lastly, the influence of the mesh (size and type) is investigated.

\section{Description of the valve}

Figure 3 illustrates the geometry of the flush valve, used for the present study. The main path of water stream is represented by white arrows.

The narrow flow passage between the piston and the seat can be observed in part (a) of Figure 4 . The distance between piston and seat in that zone is equal to $0.8 \mathrm{~mm}$. As can be expected, numerical simulations show that cavitation can occur in this narrow flow passage where high flow velocities are encountered.

Figure 5 presents the calculation domain. Only the flow in one half of the valve is calculated due to symmetry consideration. That choice is questionable, but it appears reasonable as far as steady flows are in the scope of the study.

\section{Comparison between no cavitation model and cavitation model (fluent code)}

In this section, the flow in the flush valve is calculated first without a cavitation model and then with a cavitation model.

The first mesh, shown in Figures 6 and 7, is a tetrahedral mesh with 607210 cells. The grid of the fluid domain has been created with the pre-processor of FLUENT code [7]. The mesh size depends on the position. In order to well represent the flow field in the narrow flow

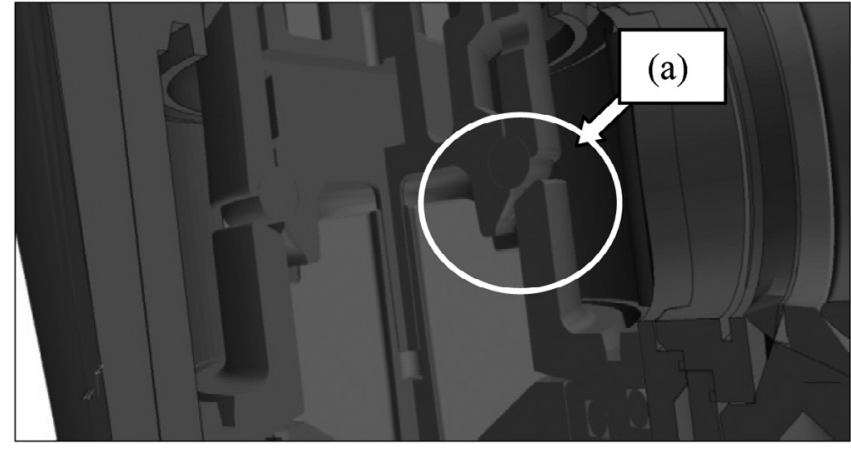

Fig. 4. Flush valve geometry (zoom on narrow flow passage).

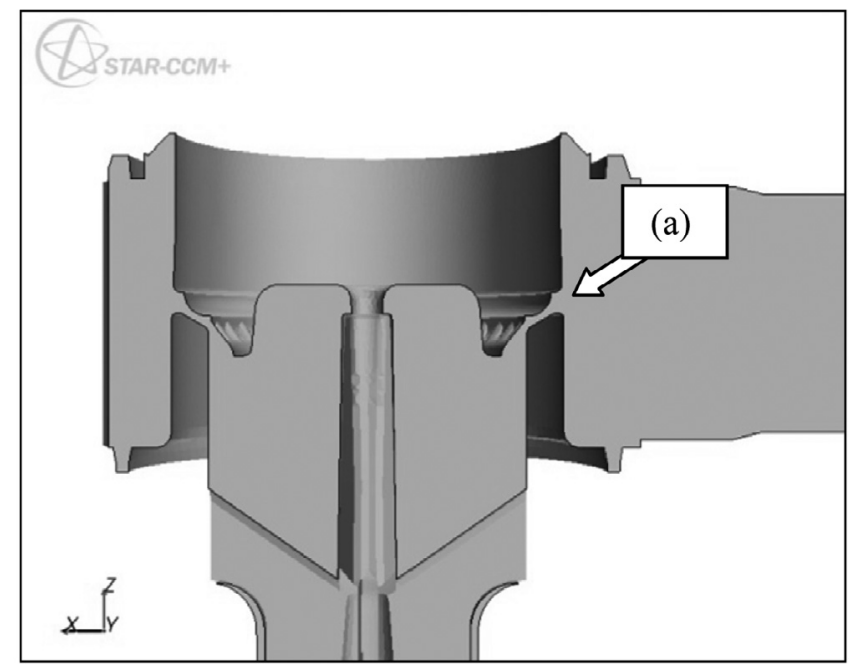

Fig. 5. Calculation domain.

passage, a refined mesh, based on the distance from the wall, is used here. The typical size of one cell varies from $0.1 \mathrm{~mm}$ in the narrow flow passage to $1 \mathrm{~mm}$ away from that passage.

Four boundaries conditions are used: walls, symmetry plane, pressure at the inlet $(0.12 \mathrm{MPa})$ and pressure at the outlet $(0 \mathrm{MPa})$.

That inlet pressure is the lowest pressure usually used in such valves [1].

The standard wall functions used in Fluent are defined in Launder and Spalding [16].

The fluid is water (density is $998.2 \mathrm{~kg} . \mathrm{m}^{-3}$, viscosity is $1.003 \times 10^{-3} \mathrm{~Pa} \mathrm{~s}$ ) for no cavitation model and mixture between water liquid and water vapour (density constant equal to $0.02558 \mathrm{~kg} \cdot \mathrm{m}^{-3}$ and viscosity to $\left.1.26 \times 10^{-6} \mathrm{~Pa} \mathrm{~s}\right)$. The density ratio between water and vapour is about 39000 . The flow is assumed incompressible (the two phases are treated as incompressible fluids), steady and turbulent. The Reynolds number based on the height of the narrow flow passage is 19000 for water and 400 for water vapour (for a maximum velocity of $\left.25 \mathrm{~m} . \mathrm{s}^{-1}\right)$. So the flow in such a valve is characterized by rather low Reynolds number. The standard $k-\omega$ turbulence model is used in both cases. The standard $k-\omega$ model in Fluent is based on the Wilcox $k-\omega$ model [17]. 


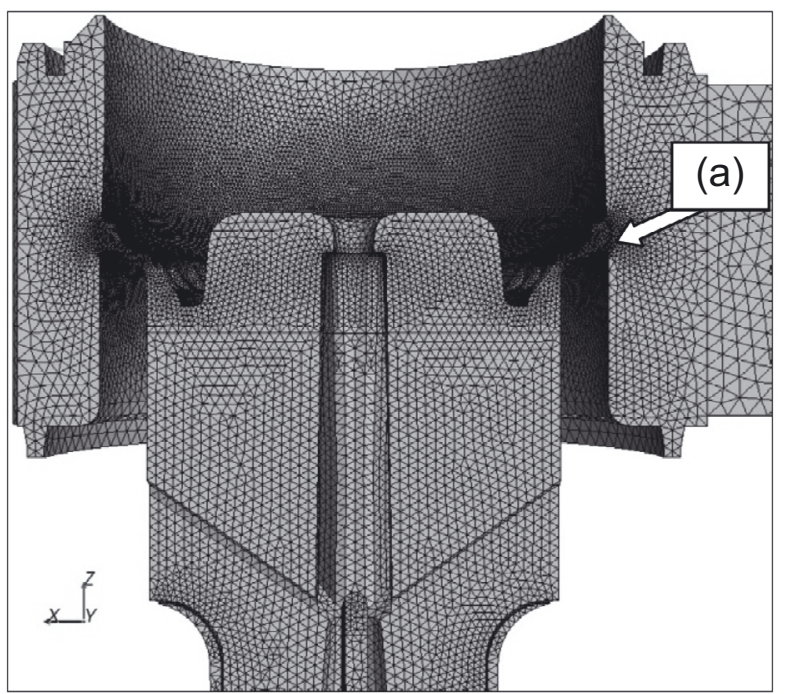

Fig. 6. Mesh of fluid zone.

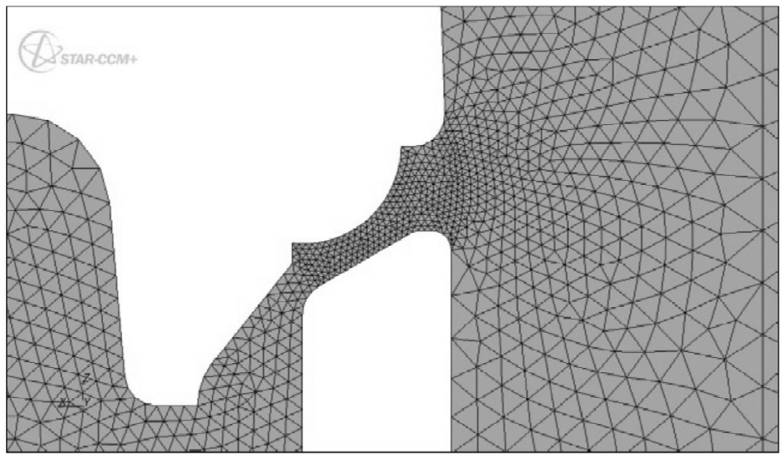

Fig. 7. Mesh detail in narrow flow passage.

The cavitation model used is based on the "full cavitation model" developed by Singhal et al. [18]. The vapour generation rate and the condensation rate are derived from the Rayleigh-Plesset equations $[7,18]$.

A steady-state solution was calculated, using the cavitation model, in order to analyse the possible development of cavitation zones within the valve, especially in the narrow flow passage. This steady solution needed about 1500 iterations: the number of iterations for which the convergence residual curves reach an asymptotic limit for each equation (continuity, $X$-momentum, $Y$-momentum, $Z$-momentum, turbulence equations and volume of fluid if used) and for mass flow rates at inlet and outlet of the calculation domain.

It is obvious that an unsteady calculation is necessary to simulate the formation and the growth of bubbles but this was not the aim of the present work.

The question of the possible use of a laminar model arises, due to the low Reynolds numbers. In fact, it must be pointed out that a liquid-vapour mixture occurs in cavitating conditions and laminar conditions are questionable in such situations. Nevertheless a calculation with laminar assumptions has been carried out in case of no cavitation hypothesis. The results are discussed in Sect. 5 .

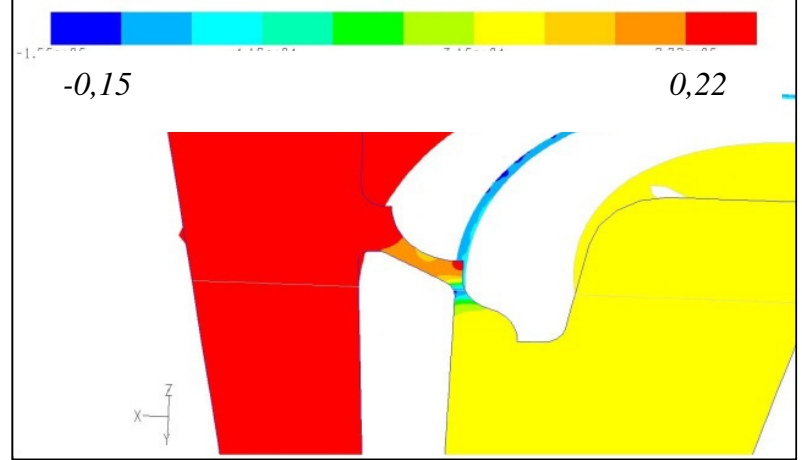

Fig. 8. Contours of absolute static pressure (MPa) with no cavitation model (FLUENT).

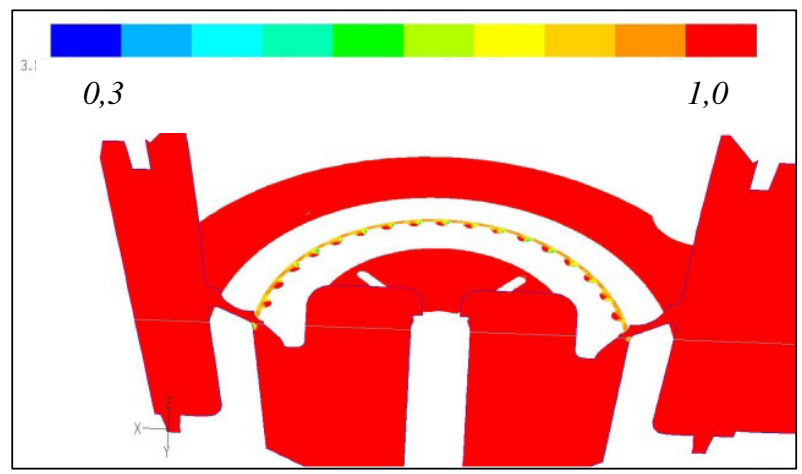

Fig. 9. Contours of volume fraction of water with a cavitation model (FLUENT).

Table 1. Results with the two models with Fluent.

\begin{tabular}{ccc}
\hline & no cavitation & cavitation \\
\hline$N_{\mathrm{it}}$ & 600 & 1500 \\
$Q\left(\mathrm{~kg} \cdot \mathrm{s}^{-1}\right)$ & 0.374 & 0.366 \\
$p_{\min }(\mathrm{MPa})$ & -0.16 & 0 \\
\hline
\end{tabular}

As a CFD code without a cavitation model is used, negative absolute pressures are obtained in some parts of the valve, more especially in the narrow flow passage, where high velocities are encountered. Figure 8 presents such results that make no physical sense. Nevertheless, this can be interpreted as a sign of cavitation risk.

The use of a CFD code with a cavitation model effectively shows that there is cavitation in this zone (Figs. 9 and 10, Tab. 1). In Figure 9 the volume fraction is used as an indication of cavitation and results show that the cavitation zone is well localized in the narrow flow passage as expected. Figure 10 presents the associated values of absolute pressure in the narrow flow passage that can be compared to the vapour pressure of water.

It can be seen in Figure 9 that the volume fraction of water $\alpha_{1}$ drops to $31 \%$ in this zone.

Table 1 presents the number of iterations, the flow rate and the minimum absolute pressure obtained with each model. The use of a cavitation model increases the number of iterations (for a steady state solution) compared to the use of a no cavitation model. The flow rates for the 


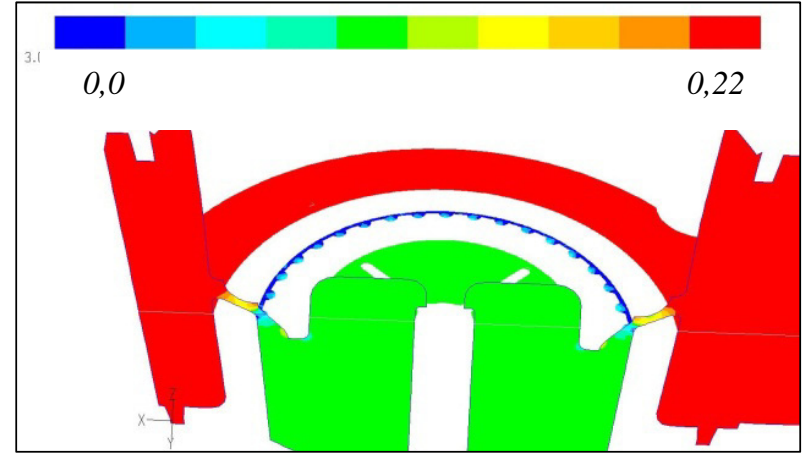

Fig. 10. Contours of absolute static pressure $(\mathrm{MPa})$ with a cavitation model (FLUENT).

two models are quite equal (the difference is lower than $2 \%$ ).

\section{Comparison between two codes}

\subsection{Model with no cavitation}

Both codes (Fluent and Star CCM+) have been compared with the same mesh (tetrahedral mesh with 607210 cells), the same boundary conditions and the same turbulence model $k$ - $\omega$.

The standard $k-\omega$ model Star CCM+ is also based on the Wilcox $k-\omega$ model [17].

The blended wall laws are used for this mesh (Fig. 7) in Star CCM+. These wall laws are intended to represent the buffer layer by appropriately blending the viscous sublayer and logarithmic regions $\left(5<y^{+}<30\right)$, where $y^{+}$is the dimensionless distance, given by Equation (2).

$$
y^{+}=u_{\tau} y / \nu
$$

$\nu$ is the kinematic viscosity, $y$ the distance from the wall and $u_{\tau}$ the friction velocity defined by Equation (3).

$$
u_{\tau}=\sqrt{\tau_{w} / \rho}
$$

$\tau_{w}$ and $\rho$ are the surface shear stress and the mass density.

For momentum, Reichardt's law $[18,19]$ is used to define dimensionless velocity $u^{+}[17]$.

$$
u^{+}=U / u_{\tau}
$$

$U$ is the flow velocity.

Overall results are given in Table 2. Minimum absolute pressure and maximum velocity are given for cell centroid base values.

Both CFD codes yield very similar results, especially for the prediction of cavitation occurrence in the narrow flow passage. Nevertheless, Table 2 shows that significant differences are observed regarding the minimum absolute pressure and the flow rate.

Even if it is clear that mesh in the narrow flow passage is rather coarse, these differences can only be explained
Table 2. Results with the two CFD simulation, no cavitation model.

\begin{tabular}{ccc}
\hline & Fluent & Star CCM+ \\
\hline$N_{\text {it }}$ & 600 & 500 \\
$Q\left(\mathrm{~kg} . \mathrm{s}^{-1}\right)$ & 0.374 & 0.540 \\
$p_{\min }(\mathrm{MPa})$ & -0.16 & -0.343 \\
$v_{\max }\left(\mathrm{m} . \mathrm{s}^{-1}\right)$ & 25 & 32.15 \\
\hline
\end{tabular}

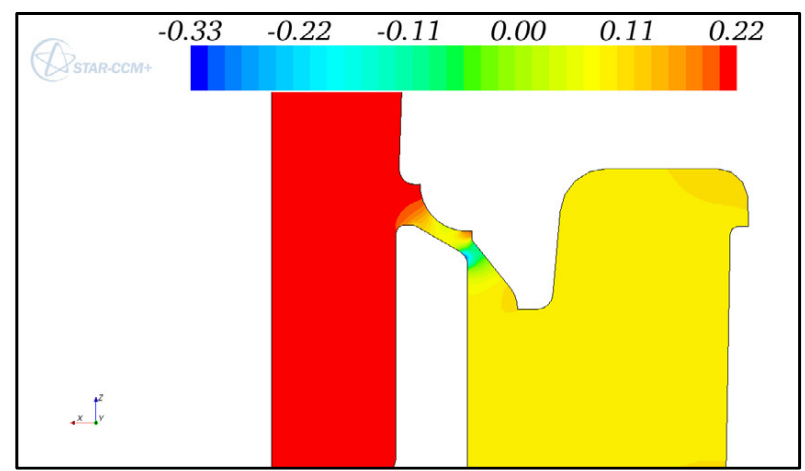

Fig. 11. Contours of absolute static pressure (MPa) with no cavitation model ( $k-\omega$ turbulence model, Star $\mathrm{CCM}+$, $x-z$ plane view).

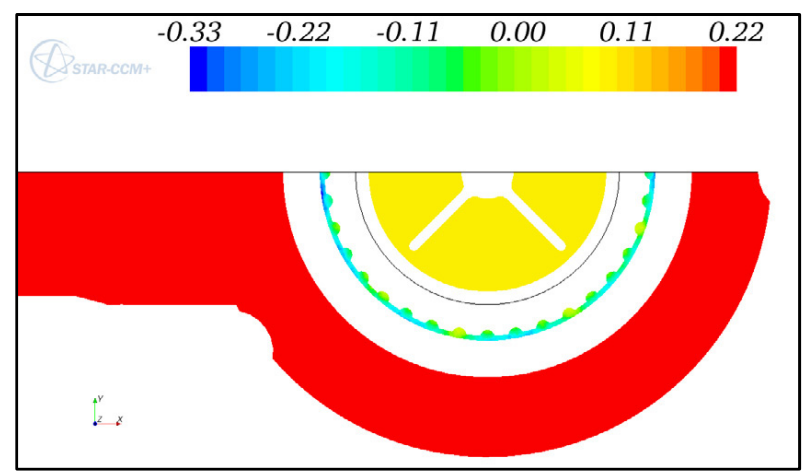

Fig. 12. Contours of static pressure (MPa) with no cavitation model ( $k-\omega$ turbulence model, Star $\mathrm{CCM}+, x-y$ plane view).

by difference in solver as calculations were made with the same mesh and the same boundary conditions.

Figures 11 and 12 present contours of absolute pressure (in case of no cavitation model) in two planes for the narrow flow passage cavitation.

Figure 13 shows what is called the cavitating zone in the valve. Here, contours of negative values of absolute pressure are used to define the occurrence of cavitation (pressures in white areas of the plot are positive).

\subsection{Model with cavitation}

Results are compared for the same mesh model (tetrahedral mesh with 607210 cells) and the same boundary conditions, using $k-\omega$ turbulence model for Fluent and $k-\varepsilon$ realizable two-layer turbulence model in Star CCM+ $[20,21]$. This model combines the realizable $k$ - $\omega$ model with the two-layer approach. The realizable 


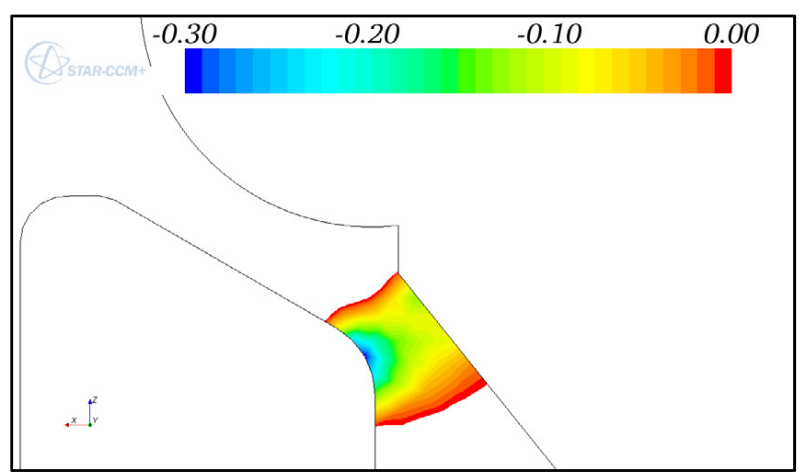

Fig. 13. Contours of static pressure $(\mathrm{MPa})$ with no cavitation model ( $k-\omega$ turbulence model): zones where pressure is lower than vapour pressure (Star CCM+).

Table 3. Results with the two CFD simulations, with cavitation model.

\begin{tabular}{ccc}
\hline & Fluent & Star CCM+ \\
\hline Turbulence model & $k-\omega$ & $k-\varepsilon$ \\
\hline$N_{\text {it }}$ & 1500 & 1000 \\
$Q\left(\mathrm{~kg} . \mathrm{s}^{-1}\right)$ & 0.366 & 0.409 \\
$p_{\min }(\mathrm{MPa})$ & 0 & -0.028 \\
$v_{\max }\left({\mathrm{m} . \mathrm{s}^{-1}}^{-1}\right)$ & 25 & 20.9 \\
$\alpha_{1} \min$ & 0.31 & 0.41 \\
\hline
\end{tabular}

turbulence model is called this because it allows the model to satisfy certain mathematical constraints on the normal stresses consistent with the physics of turbulence, so more realizable. The $k-\omega$ turbulence model led to some convergence problem with this mesh when Star CCM+ is used. This is the reason why the $k$ - $\varepsilon$ turbulence model was used with Star CCM+.

Rayleigh-Plesset equations are used in the two codes to calculate vapour generation rate and condensation rate.

The cavitation model in star CCM+ is based on the work from Sauer [22].

Table 3 summarizes results of cavitation simulation with both codes. Both codes predict occurrence of cavitation in the valve. As can be seen in Table 3, results are in better agreement than those obtained without a cavitation model.

In Star CMM+ code, negative absolute pressures are also encountered.

The cavitation zones are described in Figure 14, using the volume fraction of water $\alpha_{1}$ as indicator.

\section{Influence of turbulence model}

Star CCM+ code has been used to look at the influence of the choice of the turbulence model on the results. Calculations have been made with the same mesh (tetrahedral mesh with 607210 cells) and the same boundary conditions. A laminar model has also been used. Some convergence problems were encountered in this case, and an initial condition taken out from a turbulent calculation was used in order to get a converged solution. There

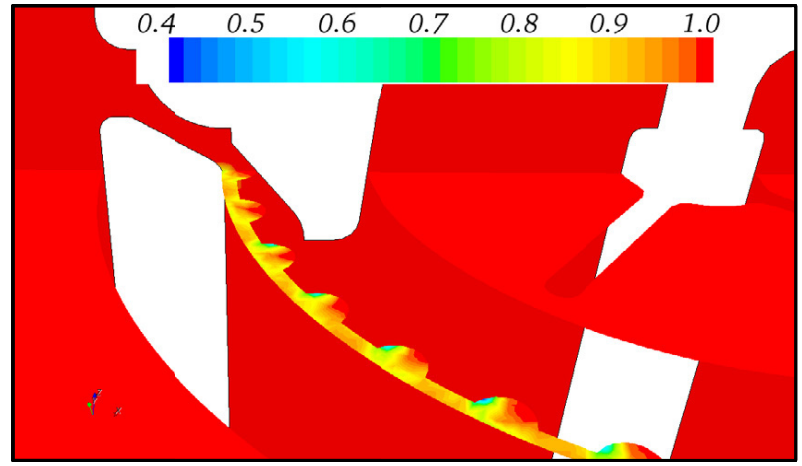

Fig. 14. Contours of volume fraction of water with cavitation model with Star CCM+.

Table 4. Results with different turbulence models, no model cavitation (Star CCM+).

\begin{tabular}{cccc}
\hline Turbulence model & $k-\omega$ & $k-\varepsilon$ & laminar \\
\hline$Q\left(\mathrm{~kg} . \mathrm{s}^{-1}\right)$ & 0.540 & 0.541 & 0.531 \\
$p_{\min }(\mathrm{MPa})$ & -0.359 & -0.343 & -0.300 \\
$v_{\max }\left(\mathrm{m} . \mathrm{s}^{-1}\right)$ & 32.15 & 31.62 & 31.39 \\
\hline
\end{tabular}

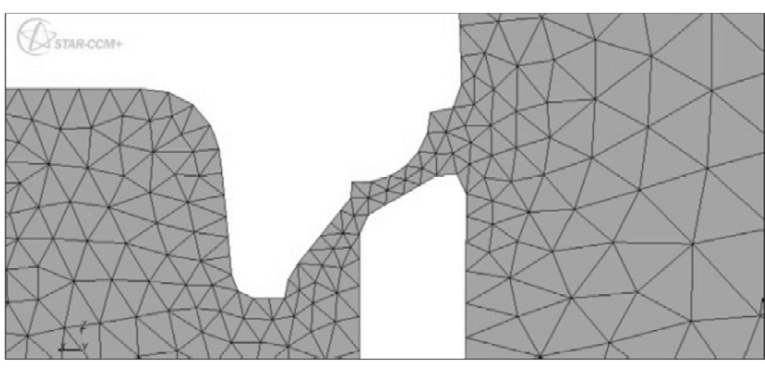

Fig. 15. Case T1: 166842 tetrahedral cells.

were no further developments with this laminar flow hypothesis as the flow is clearly turbulent, especially in the narrow flow passage.

As can be seen in Table 4, the values of the flow rate, the minimum absolute pressure and the maximum velocity are not very much dependent on the choice of the turbulence model.

\section{Influence of mesh size}

Star CCM+ has been used to analyse the mesh size sensitivity of the numerical results.

In each case, tetrahedral cells have been used. Numerical tests have been made using the same boundary conditions, the same $k$ - $\omega$ turbulence model, with realizable $k-\varepsilon$ two-layer, and no cavitation model. The mesh has been mainly refined in the narrow flow passage, as can be observed in Figures 15 to 17. Results, summarized in Table 5, show little influence regarding the cavitation area, the minimum absolute pressure and the maximum velocity in the narrow flow passage. 


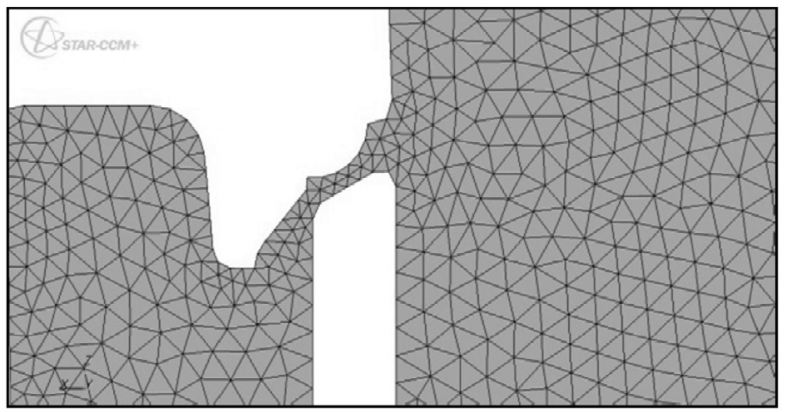

Fig. 16. Case T2: 239771 tetrahedral cells.

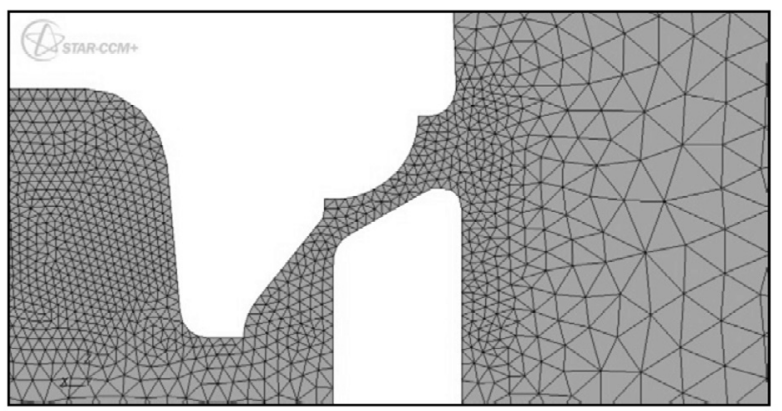

Fig. 17. Case T3: 832211 tetrahedral cells.

Table 5. Results with different numbers of cells, no cavitation model and tetrahedral mesh (Star CCM+).

\begin{tabular}{cccc}
\hline case & $\mathrm{T} 1$ & $\mathrm{~T} 2$ & $\mathrm{~T} 3$ \\
\hline$N_{\text {cells }}$ & 166842 & 239771 & 832211 \\
$Q\left(\mathrm{~kg} . \mathrm{s}^{-1}\right)$ & 0.464 & 0.474 & 0.474 \\
$p_{\min }(\mathrm{MPa})$ & -0.201 & -0.218 & -0.218 \\
$v_{\max }\left(\mathrm{m} . \mathrm{s}^{-1}\right)$ & 26.08 & 25.59 & 25.6 \\
\hline
\end{tabular}

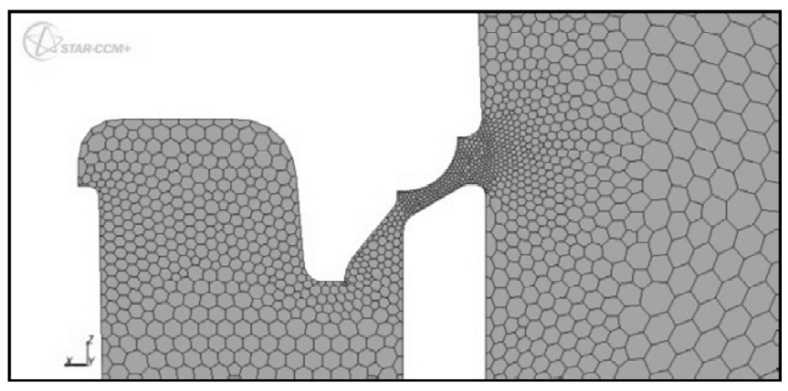

Fig. 18. Case P0: 167988 polyhedral cells.

\section{Influence of mesh type}

\subsection{Polyhedral mesh without prism layer}

Star CCM+ has been used to analyse the influence of mesh type, using polyhedral cells. In each case, the $(k-\varepsilon)$ model with realizable $(k-\varepsilon)$ two-layer has been used with no cavitation model. Polyhedral mesh has also been tested with various numbers of cells as can be seen in Figures 18 to 20.

In Star CCM+, the volume mesh is built from the surface mesh. The same surface mesh with triangular cells

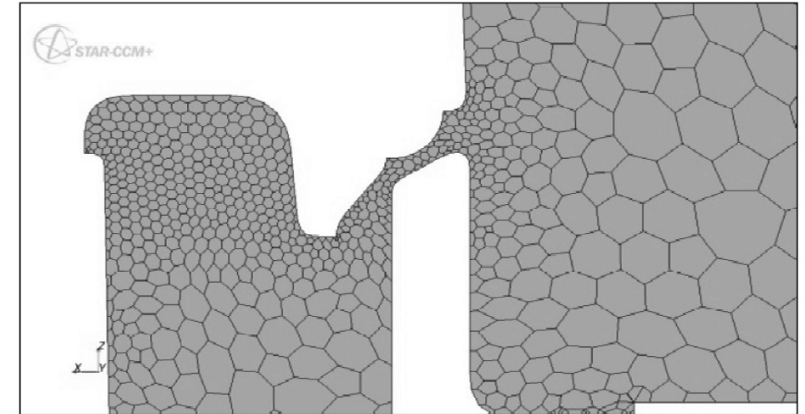

Fig. 19. Case P1: 79006 polyhedral cells.

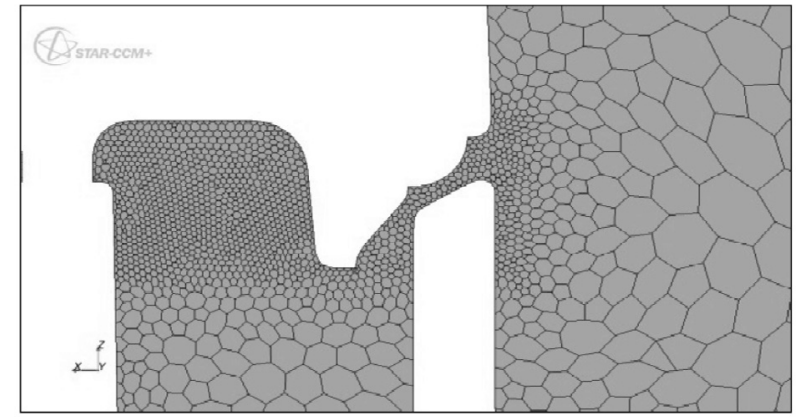

Fig. 20. Case P2: 142684 polyhedral cells.

Table 6. Results with different numbers of cells, no cavitation model and polyhedral mesh (Star CCM+).

\begin{tabular}{cccc}
\hline case & $\mathrm{P} 0$ & $\mathrm{P} 1$ & $\mathrm{P} 2$ \\
\hline$N_{\text {cells }}$ & 167988 & 79006 & 142684 \\
$Q\left(\mathrm{~kg} . \mathrm{s}^{-1}\right)$ & 0.538 & 0.512 & 0.532 \\
$p_{\min }(\mathrm{MPa})$ & -0.222 & -0.199 & -0.207 \\
$v_{\max }\left(\mathrm{m} . \mathrm{s}^{-1}\right)$ & 27.5 & 26.26 & 27.94 \\
\hline
\end{tabular}

can generate tetrahedral mesh or polyhedral mesh with or without prism layer. The basic tetrahedral mesh used in this paper (607 210 cells, Fig. 7) and the P0 mesh (Fig. 18) have the same surface mesh.

Results (given in Tab. 6) show that the mesh size, for a polyhedral mesh, has only a small influence on the three proposed criteria. Consequently the use of a coarse grid can allow a decrease of calculation time.

These polyhedral meshes give results that are comparable to those obtained with Fluent and tetrahedral mesh, regarding minimum absolute pressure and maximum velocity in narrow flow passage (Tab. 2). For a same reference surface mesh, polyhedral mesh needs fewer cells (607210 cells for a tetrahedral mesh and 167988 for a polyhedral). The flow rate remains noticeably higher with Star CCM+ than with Fluent which is not yet explained.

\section{2 polyhedral mesh with prism layer}

Prismatic near-wall layers have been included in the previous P0 mesh by using the prism meshing model in the volume meshing process (Fig. 21). For the same 


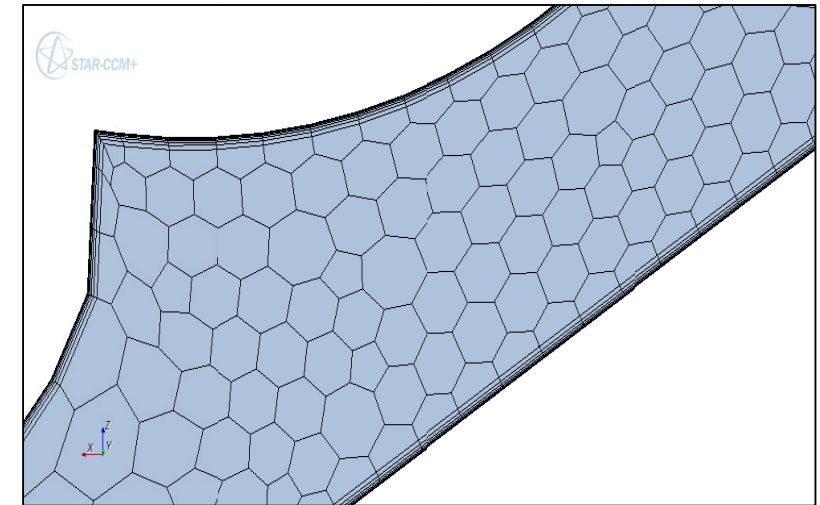

Fig. 21. Prismatic near wall layers.

Table 7. Results with different numbers of cells, no cavitation model, polyhedral mesh and prism layer (Star CCM+).

\begin{tabular}{cccc}
\hline case & PL1 & PL2 & PL3 \\
\hline$N_{\text {cells }}$ & 308066 & 308066 & 399859 \\
$e_{\mathrm{t}}$ & 10 & 20 & 20 \\
$e_{1}$ & 2.11 & 4.22 & 1.51 \\
$Q\left(\mathrm{~kg} . \mathrm{s}^{-1}\right)$ & 0.404 & 0.372 & 0.386 \\
$p_{\min }(\mathrm{MPa})$ & -0.079 & -0.021 & -0.025 \\
$v_{\max }\left(\mathrm{m} . \mathrm{s}^{-1}\right)$ & 22.7 & 20.84 & 21.2 \\
$N_{\mathrm{pl}}$ & 3 & 3 & 5 \\
wall $y_{\max }^{+}$ & 2.34 & 4.33 & 2.13 \\
\hline
\end{tabular}

surface mesh, Star CCM+ creates a volume mesh including the prism layer model. A prism layer mesh is composed of orthogonal prismatic cells that are located in the vicinity of wall boundaries as can be seen in Figure 21.

With this kind of mesh, the near wall region does not need wall functions because the near wall region is resolved all the way down to the wall.

Table 7 summarizes the consequences of the use of that prism layer mesh, with polyhedral cells, the same boundary conditions and no cavitation model. Calculations used a $k$ - $\omega$ turbulence model with a total prism layer thickness, $e_{\mathrm{t}}$, equal to $10 \mu \mathrm{m}$ or $20 \mu \mathrm{m}$, a number of prism layers $N_{\text {pl }}$ equal to 3 or 5 , a prism layer stretch factor of 1.5 and a first prism layer thickness $e_{1}$.

$$
e_{\mathrm{t}}=\sum_{i=1}^{N_{\mathrm{pl}}} 1.5^{(i-1)} e_{1}
$$

In order to obtain good convergence of the calculations, using such a mesh (Fig. 22), it has been necessary to decrease under-relaxation parameters for turbulence equations.

For a total prism layer thickness equal to $10 \mu \mathrm{m}$ and for a number of prism layers equal to 5 , calculations did not converge. This problem seems to be associated with a tiny first prism layer thickness (less than $1 \mu \mathrm{m}$ ).

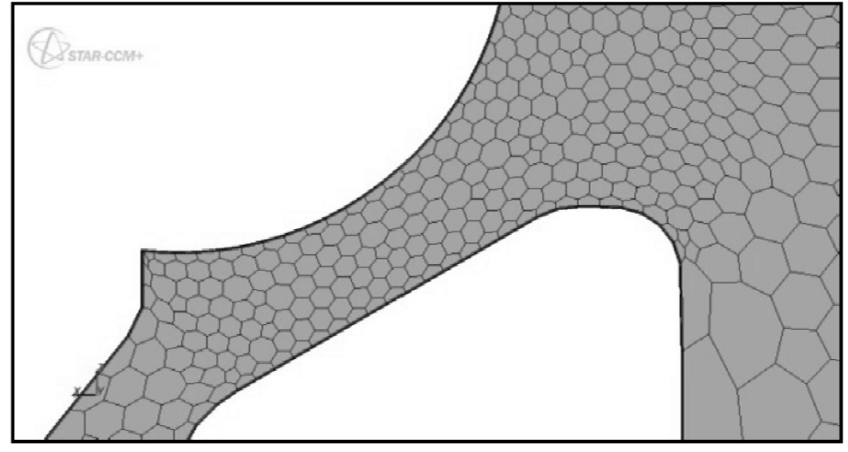

Fig. 22. Case PL1: 308066 hexahedral cells.

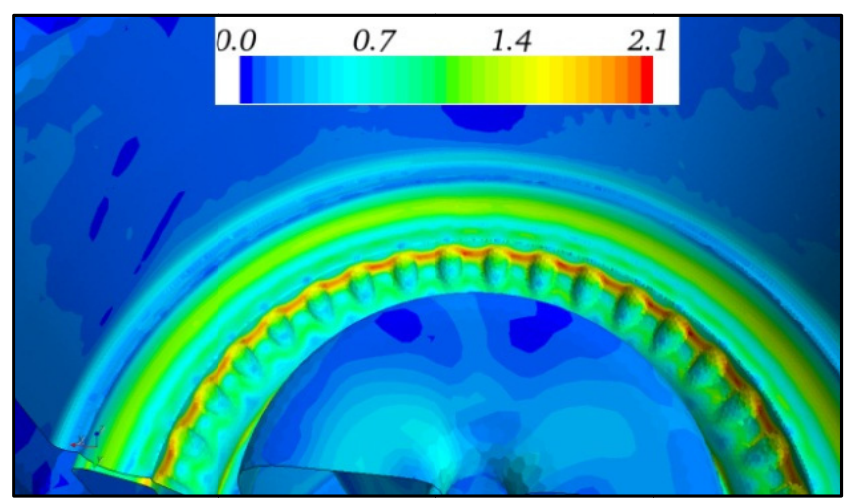

Fig. 23. Case PL3: wall $y^{+}$.

Table 7 shows that, for the three cases presented, the maximum value of dimensionless distance wall $y^{+}$remains lower than 5 (value proposed by Pope [23] for a viscous sub-layer). The parameter wall $y^{+}$represents $y^{+}$near the wall, given by Equation (2) in which y is equal to first prism layer thickness, $e_{1}$. This maximum value occurs in the narrow flow passage as can be seen in Figure 23. PL1 and PL3 cases lead to some equivalent values of wall $y^{+}$, for an equivalent prism layer thickness. The first prism layer thickness seems to have a great importance in these cases.

Furthermore, for the PL3 case, the flow rate reaches the one obtained previously with Fluent in Table 2, which is well correlated to experimental data. It may also be noticed that lower values of maximum velocities (and associated higher values of minimum negative pressure) are obtained with that kind of mesh.

\section{Influence of inlet pressure}

With the first mesh (607210 cells) numerical simulation was performed with a relative inlet total pressure equal to $0.25 \mathrm{MPa}$ (conditions of normalized tests [1]).

A minimum absolute pressure equal to $-1 \mathrm{MPa}$, a flow rate equal to $0.786 \mathrm{~kg} . \mathrm{s}^{-1}$ and a maximum velocity equal to $42.59 \mathrm{~m} . \mathrm{s}^{-1}$ were obtained.

As can be observed in Figure 24, the domain with negative values of absolute pressure (indicating cavitation 


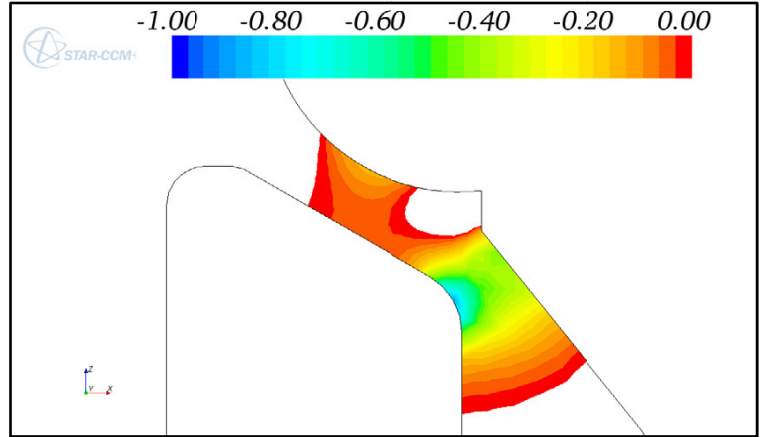

Fig. 24. Pressure contours $(\mathrm{MPa})$ for inlet pressure of $0.25 \mathrm{MPa}$.

if no cavitation model is used) is much more extended than with an inlet pressure equal to $0.12 \mathrm{MPa}$ (Fig. 13). This can be associated with a consequence of the large increase of flow velocities in the narrow flow passage.

\section{Conclusions}

Simulations of flow in a flush valve, in a position between full opening and full closure, have been performed using two CFD codes (Fluent and Star CCM+), in steady conditions, with and without a cavitation model.

Without using a cavitation model, results exhibit regions where the pressure is negative or slightly lower than the water vapour pressure. These parts of the flow domain are interpreted as cavitating zones.

Examination of water vapour fraction with use of a cavitation model applied in both CFD codes confirms that cavitation indeed occurs in these regions. This conclusion has been confirmed for various values of pressure at inlet of the valve.

So, it can be said that the use of a CFD analysis with a single phase hypothesis can be accurate enough in order to get an estimation of cavitating zones in such a complex system. Of course this is of practical interest for the design phase of a new product as calculation time is far lower when no use of a cavitation model is made.

The influences of turbulence model, mesh size and mesh type have also been studied. Even with coarse mesh, cavitation was predicted rather accurately without using a cavitation model. When using a cavitation model, one has to be very careful with a lot of parameters regarding the mesh and under-relaxation parameters. The comparison with some experimental data showed that the use of polyhedral mesh and prism layers appeared to be the most efficient.

The numerical studies have of course been used to analyse in detail the quality of the flow within the whole valve in order to enhance flow distortions, turbulence levels and cavitation risks. The present paper has been limited to the analysis of cavitation zones within the valve. The proposed numerical methodology has been used for the development of new designs. The study may help the manufacturer to reduce the number of prototypes and the number of associated tests.

The development of a calculation procedure allowing for the simulation of the entire transient operation of such a valve will be undertaken. Then, simulation of the interaction between flow and structure will become possible in order to get an accurate prediction of noise emission from such a device.

\section{References}

[1] NF EN 12541, Pressure flushing valves and automatic closing urinal valves (PN10), ICS 91.140.70, 2003

[2] BS EN ISO 3822-3/A1, Acoustic laboratory tests on noise emission from appliances and equipment used in water supply installations, 1997

[3] J. Romeu, S. Jiménez, R. Capdevilla, Noise emitted by water supply installations, Applied Acoustics 65 (2004) 401-419

[4] Y. Lecoffre, Cavitation Bubbles Trackers, Balkema. 399 pp. ISBN 905410783 9. 75 Hfl., 1999

[5] C.E. Brennen, Cavitation and bubbles dynamics, Oxford University Press, ISBN 0-19-509409, 1995, pp. 291

[6] H. Gao, X. Fu, H. Yang, T. Tsukiji, Numerical investigation of cavitating flow behind a poppet valve in water hydraulic system, Journal of Zheijang University Science V3 4 (2002) 395-400

[7] Fluent documentation user's guide

[8] Star CCM+ documentation

[9] A.H. Chorin, Numerical Solution of Navier-Stokes equations, Mathematics of computation, 1968, 22-745-762

[10] I. Demirdzic, Z. Lilek, M. Peric, A collocated finite volume method for predicting flows at all speeds, Int. J. Num. Methods Fluids 16 (1993) 1029-1050

[11] I. Demirdzic, S. Musaferija, Numerical method for coupled fluid flow, heat transfer and stress analysis using unstructured moving meshes with cells of arbitrary topology, Comput. Methods Appl. Mech. Eng. (1995) 1-21

[12] J.H. Ferziger, M. Peric, M. Computational Methods for Fluid Dynamics, 3rd rev. ed., Springer-Verlag, Berlin, 2002

[13] S.R. Mathur, J.Y. Murthy, Pressure-based method for unstructured meshes, Numerical Heat Transfer, Part B: Fundamentals 31 (1997) 195-214

[14] S.R. Mathur, J.Y. Murthy, Pressure boundary conditions for incompressible flow using unstructured meshes, Numerical Heat Transfer, Part B: Fundamentals 32 (1997) 283-298

[15] M. Peric, R. Kressler, G. Scheuerer, Comparison of finitevolume numerical methods with staggered and colocated grids, Computers \& Fluids 16 (1988) 389-403

[16] B.E. Launder, D.B. Spalding, The Numerical Computation of Turbulent Flows, Comp. Methods Appl. Mech. Eng. 3 (1974) 269-289

[17] D.C. Wilcox, Turbulence Modeling for CFD. DCW Industries, Inc., La Canada, California, 1998 
[18] A.K. Singhal, H.Y. Li, M.M. Athavale, Y. Jiang, Mathematical Basis and Validation of the Full Cavitation Model, ASME FEDSM'01, New Orleans, Louisiana, 2001

[19] H. Reichardt, Vollstaendige Darstellung der turbulenten Geschwindigkeitsverteilung in glatten Leitungen, Z. Angew. Math. Mech. 31 (1951) 208-219

[20] M. Wolfstein, The velocity and temperature distribution in one-dimensional flow with turbulence augmentation and pressure gradient, Int. J. Heat Mass Trans. 12 (1969) $301-318$
[21] T.H. Shih, W.W. Liou, A. Shabbir, Z. Yang, J. Zhu, A New $k-\varepsilon$ Eddy Viscosity Model for High Reynolds Number Turbulent Flows - Model Development and Validation", NASA TM 106721, 1994

[22] J. Sauer, Instationaer kavitierende Stroemungen - Ein neues Modell, basierend auf Fron Capturing VOF und Blasendynamik, Dissertation, Universitaet Karlsruhe, 2000

[23] S.B. Pope Turbulent Flows, Cambridge University Press, 2000, pp. 771, ISBN 0-521-59886-9 